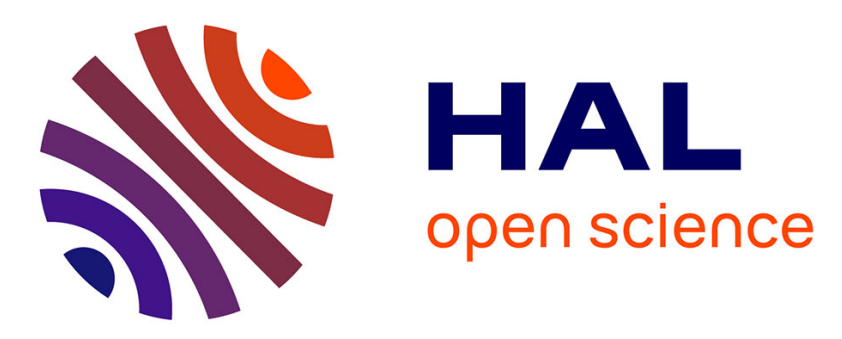

\title{
Multiple delay nonlinear wavelength dynamics for photonic Reservoir Computing
}

R. Martinenghi, L. Appeltant, S. Rybalko, G. van Der Sand, J. Danckaert, M. Jacquot, Y.K. Chembo, L. Larger

\section{- To cite this version:}

R. Martinenghi, L. Appeltant, S. Rybalko, G. van Der Sand, J. Danckaert, et al.. Multiple delay nonlinear wavelength dynamics for photonic Reservoir Computing. 2011 Conference on and 12th European Quantum Electronics, May 2011, Munich, Germany. pp.EH4_5, 10.1109/CLEOE.2011.5943557. hal-00661165

\section{HAL Id: hal-00661165 https://hal.science/hal-00661165}

Submitted on 24 Mar 2021

HAL is a multi-disciplinary open access archive for the deposit and dissemination of scientific research documents, whether they are published or not. The documents may come from teaching and research institutions in France or abroad, or from public or private research centers.
L'archive ouverte pluridisciplinaire HAL, est destinée au dépôt et à la diffusion de documents scientifiques de niveau recherche, publiés ou non, émanant des établissements d'enseignement et de recherche français ou étrangers, des laboratoires publics ou privés. 


\title{
Multiple delay nonlinear wavelength dynamics for photonic Reservoir Computing
}

\author{
R. Martinenghi', L. Appeltant ${ }^{2}$, S. Rybalko ${ }^{1}$, G. Van der Sand ${ }^{2}$, \\ J. Danckaert ${ }^{2}$, M. Jacquot ${ }^{1}$, Y. Chembo ${ }^{1}$ L. Larger ${ }^{1}$ \\ 1.University of Franche-Comté \& FEMTO-ST/Optics Dpt., UMR CNRS 6174, 16 route de Gray, F-25030 Besançon, France \\ 2. Applied Physics Research Group (APHY), Vrije Universiteit Brussel, Pleinlaan 2, 1050 Brussels, Belgium
}

Reservoir Computing is an emerging field of research intended to develop novel computational machines based on operating principles issued from the neural network community [1] and the brain research sciences [2]. Practical implementations of the corresponding principles is a strongly open question, which is precisely addressed from the photonic viewpoint in the frame of a recently funded EC project PHOCUS. The main idea is here to benefit from the intrinsic dynamic complexity of delay systems, which experimental realization are well known in photonics, in order to perform the central role of a reservoir computer, the reservoir itself.

In its original formulation, the reservoir is typically a network of nonlinear dynamical nodes, thus forming a spatially extended network of interconnected nodes. Roughly speaking, the computational power of the Reservoir comes from the expansion of an original complex problem (input data to be analyzed), onto the even more complex and higher dimensional phase space of the reservoir, in which it is expected that a linear separation (hyperplane) can be found for solving the problem formulated in the input data. The processing of such a problem by a Reservoir Computer can be summarized as follows (Fig.1, left): input data are formatted as a temporal representation of the original problem, and used as an excitation signal for the Reservoir; the Reservoir dynamical response to this excitation is then analyzed by "learning" a suitable linear Read-Out combination of some points of the huge Reservoir phase space (a set of known pairs of input data \& problem solution are required for this learning step); the learnt Read-Out can then be used to analyze the Reservoir response of other input data of the same class of problem, for which the Reservoir can give the a priori unknown solutions.
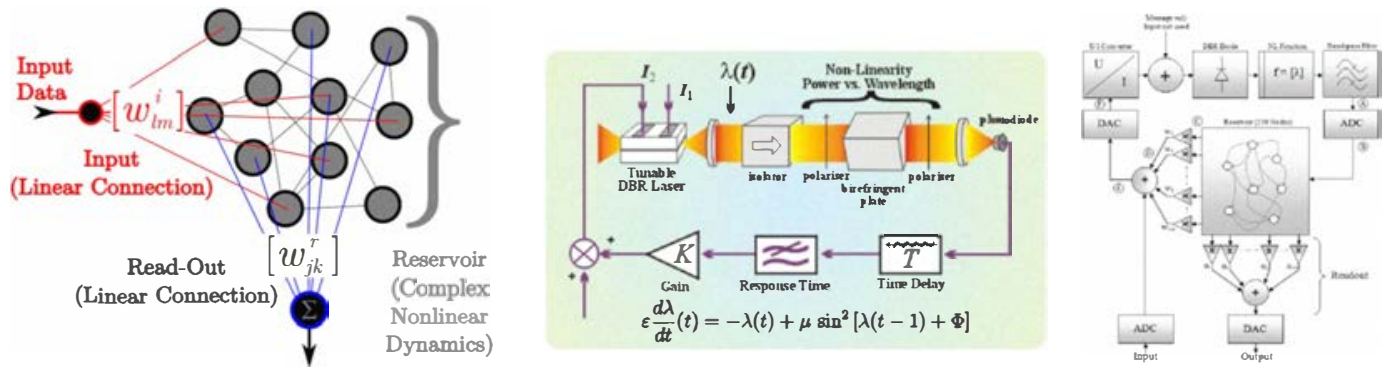

Fig. 1 Left: principle of a Reservoir Computer; center: wavelength delay dynamics; right:wavelength dynamics with multiple delay and Read-Out implemented by an FPGA.

Since delay dynamics are characterized by an infinite dimensional phase space as for spatio-temporal dynamical systems like a network of nodes, it is reasonable to think about them for the realization of a Reservoir. Nodes of the Reservoir can be virtually defined using the time-space representation of delay dynamics [3], and nodes connectivity can be viewed as delays connecting different temporal positions within a global time delay: multiple delay dynamics is expected to form a highly connected network of nodes. In order to test experimentally such a configuration, we used a previously designed wavelength chaos generator (Fig.1, center [4]), and combined it to an FPGA (field programmable gate array) allowing to perform both the multiple delayed feedback, and the linear Read-Out (Fig.1, right). In order to test the computational power of the approach, we implemented a standard test called NARMA, and consisting of the output calculation of a noise driven nonlinear iteration. Normalized root mean square error from the Reservoir output could be obtained below 0.3 .

We will report on the photonic implementation, the numerical simulations of the corresponding Reservoir subjected to the NARMA sequences, and the computational power results we have obtained both numerically and experimentally.

\section{References}

[1] H. Jaeger, "The "echo state" approach to analysing and training recurrent neural networks", Technical Report GMD, 148, German National Research Center for Information Technology, (2001).

[2] W. Maass, T. Natschläger, H. Markram, "Real-Time Computing Without Stable States: A New Framework for Neural Computation Based on Perturbations", Neural Comput., 14, 2531 (2002).

[3] F.T. Arecchi, G. Giacomelli, A. Lapucci, R. Meucci, "Two-dimensional representation of a delayed dynamical system", Phys. Rev. A, 45, R4225 (1993).

[4] J.-P. Goedgebuer, L. Larger, H. Porte, "Optical cryptosystem based on synchronization of hyperchaos generated by a delayed feedback tunable laserdiode", Phys. Rev. Lett., 80, 2249 (1998). 